\title{
Adolescência e Jovem Adultícia: Crescimento Pessoal, Separação-Individuação e o Jogo das Relações ${ }^{1}$
}

\author{
Catarina Pinheiro Mota ${ }^{2}$ \\ Universidade de Trás-os-Montes e Alto Douro \\ Magda Rocha \\ Universidade Católica Portuguesa, Centro Regional do Porto
}

\begin{abstract}
RESUMO - O presente artigo procura problematizar a importância das dinâmicas relacionais no crescimento pessoal. Tendo como ponto de partida a teoria da apego, o desenvolvimento pessoal é pautado por processos de separação-individuação; são estes os processos que permitem a construção de um sentido de autonomia. Recentemente o conceito de "adultos emergentes" tem vindo a ganhar destaque, gerindo a discussão em torno dos factores internos e externos que eventualmente potenciam a entrada na adultícia. Pais, irmãos e pares assumem relevância neste processo, o que implica posteriormente um alargamento da rede social ao contexto de trabalho e às relações amorosas. As implicações desta transição serão discutidas à luz do processo de separação-individuação e dos factores moderadores do crescimento pessoal.
\end{abstract}

Palavras-chave: adolescência; adultez emergente; apego; separação-individuação; família, amigos e pares.

\section{Adolescence and Emerging Adulthood: Personal Growth, Separation-Individuation and the Relational Game}

\begin{abstract}
The purpose of the present article is to discuss the importance of the relationship dynamics in personal development. Taking the attachment theory as a starting point, the personal development path is guided by separationindividuation processes; these processes allow building a sense of autonomy. Recently the concept of "emerging adults" has gained importance, managing the debate around the internal and external factors that may enhance the entry into adulthood. Parental figures, siblings and peers assume a relevant role in the process, supporting the adolescent's inclusion in broader social contexts like work and romantic relationships. The implications of this transition will be discussed according to the separation-individuation process and moderating factors of personal growth.
\end{abstract}

Keywords: adolescence; emerging adulthood; attachment; separation-individuation; parents, friends and peers.

Nas últimas décadas, a transição da adolescência para a fase adulta tem vindo a ganhar relevância como objecto de estudo por parte da comunidade científica. Actualmente parece estar mais claro o papel da adolescência como antecedente de desenvolvimento à entrada na vida adulta, reflectindo a transição para a independência e a consolidação da autonomia. O desenvolvimento sublinha a necessidade de um processo de (re)estruturação interna a que o sujeito psicológico está submetido ao longo de todo o ciclo de crescimento pessoal, mas que na adolescência se torna mais premente pela imposição de sucessivos conflitos identitários, nomeadamente a individuação face à família, implicando a autonomia, em paralelo com a identificação com o grupo de pares, e posteriormente a integração da perspectiva do outro no self pessoal, sobretudo através das relações com o par amoroso (Hendry \& Kloep, 2002). Estes desafios de identidade exigem uma resolução balanceada para que a entrada no patamar do desenvolvimento que se avizinha, a adultícia, seja efectuada de forma adaptativa.

1 A editoria associada da revista optou por manter a grafia do português de Portugal.

2 Endereço para correspondência: Departamento de Educação e Psicologia - Edifício do CIFOP - Rua Dr. Manuel Cardona - UTAD, Apartado 1013, 5001-558, Vila Real. Portugal.E-mail: catppmota@utad.pt.
Por outro lado, Arnett (2006) e Bynner (2005) são autores que destacam a pertinência no reconhecimento e na análise das diferenças no processo de separação e individuação de jovens adultos, sublinhando as divergências encontradas entre jovens oriundos de distintos contextos socioculturais, nomeadamente entre aqueles provenientes dos Estados Unidos e da Europa. Estas diferenças são descritas à luz de factores moderadores que se prendem, entre outros, com a classe social, as escolhas de carreira e qualificações académicas, e ainda com factores aliados à empregabilidade. Em simultâneo, e ainda de acordo com Arnett (2006), ao contrário do que acontecia há cerca de 30 anos, as expectativas em torno da aceitação de si enquanto adulto e a construção de uma vida familiar distinta da família nuclear, não se centram na questão etária. Assim, o autor aponta para a necessidade de perspectivar a entrada na adultícia enquadrando-a no seu estádio imediatamente anterior, caracterizado pela necessidade de "experimentar". A questão relaciona-se com a mudança de interesses, agora mais direccionados para o investimento na educação para a carreira ou na exploração de realidades sociais distintas (e.g., através do viajar), em suma, o que Ravn (2005) designa por experimentação do "sabor da vida". De encontro a esta perspectiva, reflecte-se acerca da importância que o processo de separação-individuação assume face à qua- 
lidade das relações com as figuras primárias de prestação de cuidados. Neste sentido, a internalização de modelos de base segura dos pais em adolescentes e jovens adultos surge como um dos facilitadores no processo de autonomia. A separação sugere um passo relevante no desenvolvimento dos jovens, constituindo-se num preditor do alargamento da rede de apoio emocional. Ela não pressupõe uma ruptura com o contexto emocionalmente significativo da relação parental. Ao contrário, é no seio de relações onde é permitido aos jovens que se explorem a si próprios e ao mundo, mesmo que no desacordo, que se mantém a base segura, alargando potencialmente o sistema de apego a figuras alternativas de segurança (Rocha, 2008; Rocha, Mota, \& Matos, 2011). Paralelamente com os pais, os irmãos exercem por vezes o papel de porto seguro, pautado pela dinâmica da reciprocidade e da similitude das vivências, iniciando muitas vezes a aprendizagem da prestação e do receber simultâneo de apoio e cuidados, por outras palavras, o advento das relações paralelas. Por sua vez, o ensaio emocional efectuado nestas ligações representa muitas vezes a génese da qualidade dos laços estabelecidos com os pares. $\mathrm{Na}$ adolescência, as vivências no seio do grupo de pares traduzem muitas vezes a qualidade do processo de separação e de procura de autonomia face às figuras parentais.

Por seu turno, a relação com o par amoroso desempenha para os jovens um ensaio maior para futuras vivências românticas emocionalmente investidas. Ao potenciarem uma maior percepção de si e da dinâmica de si com o outro, permitem o desenvolvimento de capacidades de tolerância e respeito pelo espaço vital do outro. O percurso de afastamento/proximidade com cada uma destas figuras representa um cenário de progressiva inserção num contexto. A procura de proximidade não é obrigatoriamente física, no sentido da inclusão do sistema sexual na relação, mas implica uma ânsia de intimidade partilhada, sobretudo no final da adolescência e início da adultícia. De seguida, discutir-se-ão algumas das implicações deste processo de transição e reorganização pessoal à luz do conceito já referenciado de "adultos emergentes" (Arnett, 2006), onde se incluem as escolhas relacionais e os percursos da e na carreira que caracterizam marcadamente as vivências da vida adulta.

\section{Adolescência e Jovem Adultícia - Crescimento Pessoal}

A adolescência e jovem adultícia são etapas de desenvolvimento carregadas de mudanças e reorganizações adaptativas que vão sendo tecidas na relação com as figuras parentais, mas cada vez mais com os pares e outras figuras significativas, com relevância para o par amoroso (e.g., Eccles, Templeton, Barber, \& Stone, 2003). Todavia ao abordar a temática do crescimento pessoal dos jovens, torna-se necessário compreender a importância que o percurso emocional vivenciado desde a infância aporta para o crescimento dos adolescentes e futuros adultos. Embora na literatura seja destacada na grande maioria das vezes a importância das relações de apego na adaptabilidade futura do sujeito psicológico, não advogamos neste texto um determinismo cego relativamente ao sistema de apego. As oportunidades relacionais de contextos emocionalmente significativos podem, e muitas vezes constituem-se, em contextos alternativos de segurança à insegurança inicial. No entanto, torna-se claro que as vivências afectivas ao longo do desenvolvimento permitem a construção de modelos internos dinâmicos ${ }^{3}$, que desempenham um importante papel modelador de outras relações ao longo do ciclo vital. Os processos de atenção dirigida têm com toda a certeza um papel a desempenhar, como têm também capacidades reflexivas que o desenvolvimento permitiu, pelo que funcionar ao nível interno num quadrante inseguro na relação, por exemplo com os pais, não determina obrigatoriamente o funcionamento inseguro com o par amoroso, embora o influencie. A investigação permitiu estabelecer que um modelo do self como figura susceptível de ser amada se associa positivamente a um modelo de figura de apego disponível e facilitadora de exploração (Bretherton, 1992). As crianças que têm, por parte dos pais, apoio nos seus esforços de proximidade e também de exploração, e responsividade às suas necessidades, tendem a desenvolver imagens positivas quer do self quer dos outros (e.g., Claussen \& Crittenden, 2000). O desenvolvimento físico é acompanhado pelo crescimento emocional, ambos pautados por desafios que permanentemente se colocam à sua capacidade de adaptação, por exemplo, na adolescência, a necessidade extrema da centração em si, paralelamente à necessidade de aceitação pelos outros, de outro modo, à sua capacidade de encontrar os recursos que melhor podem satisfazer as suas necessidades básicas de inclusão e independência (Kegan, 1982). A diversidade de experiências de exploração proporcionadas representam, assim, uma importante fonte de crescimento. Deste modo, crianças capazes de experimentar deixam adivinhar figuras cuidadoras primárias capazes de potenciar essa exploração, na certeza que o regresso trará a segurança e, por isso mesmo, mais um ciclo exploratório. A criança pode ir efectuando escolhas no mundo exterior imediato, tendo a garantia de poder voltar e ser aceite, ao mesmo tempo que, se confrontado com situações de stress e ameaça, pode regressar ao conforto da segurança de um porto seguro (Bowlby, 1988). É justamente a continuidade deste processo de construção de segurança que permite que o protesto de separação apareça enquanto comportamento adaptativo, já que nem todas as relações desenvolveram este carácter seguro, e por isso mesmo, o afastamento do porto e da base segura são sentidas como ameaçadoras (Grossmann \& Grossmann, 2004). Esta dinâmica entre sistemas de apego e de exploração é necessariamente complementar, ressalvando-se, contudo, que os modelos internos dinâmicos são susceptíveis de revisão ao longo do ciclo vital.

De acordo com uma perspectiva ecológica (Bronfenbrenner, 1996), as crianças vão sendo progressivamente

3 De encontro à perspectiva de Bowlby (1988), os modelos internos dinâmicos integram mapas cognitivos, representações de esquemas que o indivíduo constrói e tem sobre si próprio e o seu comportamento, bem como dos outros e do mundo e cuja complexificação tende a aumentar. Incluem sentimentos, crenças, expectativas, estratégias comportamentais, direccionamento da atenção, interpretação de informação e organização da memória. Caracterizam-se pela capacidade de transformação e de adaptação às características dos novos períodos de desenvolvimento e contextos ao longo do ciclo de vida. 
integradas num contexto exterior cada vez mais amplo, e cada vez também mais integrando figuras com importância emocional além das figuras parentais. Crianças e adolescentes vão paulatinamente criando um distanciamento físico e temporal dos pais entendido não como detachment, mas como oportunidade de desenvolvimento de exploração, que posteriormente permite o processo de individuação, ou o constituir-se como diferenciado das relações complementares (pais) mas também das recíprocas (pares e par amoroso); é neste contexto que se desenvolve um sentido de autonomia do self (Mattanah, Brand, \& Hancok, 2004). A entrada na adolescência, a maturação física, psíquica e hormonal, acelera este processo de separação dos pais e a consequente autonomia dos jovens. As mudanças físicas (nem sempre completamente aceites), as descobertas sexuais, e as transições sociais marcam a vida dos adolescentes com uma dupla necessidade. Primeiramente, a procura de integração e aceitação fora do contexto parental, o que reflecte um sentimento de pertença e valorização pessoal; e, em simultâneo, a necessidade de manutenção do laço parental, fonte impreterível de segurança, mesmo que fisicamente mais ténue na relação directa. Por conseguinte, adolescentes seguros são caracterizados pela capacidade de se autonomizarem, mas avaliarem as suas relações com as figuras parentais enquanto bases seguras. Trata-se aqui da tarefa de desenvolvimento de encontrar o equilíbrio entre o desejo de individualidade e a permanência da ligação com os elementos da família e as figuras parentais em particular (Fleming, 2003). Por sua vez, esta dinâmica parece estar directamente ligada com a forma como os jovens gerem as suas relações. Adolescentes seguros são mais populares no grupo de pares, têm um maior número de amigos que os adolescentes inseguros, estando mais disponíveis para novos relacionamentos (Collins \& Sroufe, 1999).

Coloca-se então a questão da vulnerabilidade pessoal dos jovens com funcionamentos mais inseguros. Este funcionamento torna-se mais evidente face aos contextos externos encarados como de risco potencial. Trata-se do risco do abandono quer pela confirmação da imagem negativa de si, quer do risco de abandono perante as tentativas de procura de proximidade, porto e base seguros, que decorrem nos outros "ausentes" e/ou "inconstantes". É neste confronto com o exterior social que se torna premente a necessidade de ultrapassar conflitos internos. A este propósito, é pertinente abordar o conceito de resiliência, também ele um processo, que parece estar directamente relacionado com a dinâmica de resolução positiva dos obstáculos (ou oportunidades de desenvolvimento) que se vão colocando ao sujeito. A resiliência é potencialmente facilitada, entre outros aspectos, pela qualidade dos contextos afectivos presentes na vida dos jovens (e.g., Luthar \& Goldstein, 2004). Assim, o desenvolvimento pessoal passa pelo processo de individuação e pela forma como estes jovens percebem as suas experiências emocionais como sendo mais ou menos satisfatórias, repercutindo-se na relação com as demais figuras significativas (Buhl, 2008).

O ponto que segue dá continuidade ao tema que até aqui temos discutido, pelo que, ainda no que toca ao crescimento pessoal se destaca o significado da individuação e os desafios estruturais dos adultos emergentes. Pretende-se discutir esta transição à luz da qualidade das relações desenvolvidas, bem como face à relevância das mudanças socioeconómicas e culturais, traduzindo uma nova perspectiva da entrada na vida adulta.

\section{Separação Individuação - Adultos Emergentes e a Dinâmica Parental}

Uma das abordagens teóricas mais frequentes à emergência da adultícia diz respeito à integração no mundo do trabalho e à constituição de uma família própria. Até à década de setenta do século passado, os jovens capazes de atingir a estabilidade económica, que lhes permitia a criação do seu próprio núcleo familiar, eram considerados adultos plenos, justamente através destes dois marcos de vida. Desde então, perante as mudanças ocorridas cultural e economicamente, a entrada na vida adulta passou a ser repensada, na perspectiva de compreender as vivências dos jovens adultos em torno de necessidades pessoais que necessariamente são diversas das historicamente referenciadas, e que incluem o confronto com a entrada tardia no mercado de trabalho e a consequente permanência estendida na família nuclear. Trata-se não só de formação pessoal (na qual se destaca o investimento académico), como também da realização profissional e na mudança em torno da constituição familiar, retratando uma realidade que terá de compreender a autonomia dentro de um processo no qual os pais continuam a estar presentes.

A este propósito destacam-se algumas diferenças que têm vindo a ser reportadas na literatura, nomeadamente no que respeita à implicação de factores estruturais influenciadores desta tarefa de desenvolvimento como são o género, a classe social, a etnia ou mesmo o capital humano e cultural (Bynner, 2005). De acordo com Bynner (2005), os factores estruturais parecem associar-se ao timing da transição para a adultícia, pelo que a comparação das duas últimas décadas entre vários jovens oriundos de diferentes países da Europa traduzem, em geral, uma idade mais tardia de casamento e uma maior percentagem de investimento académico. Mais ainda, percebe-se uma certa alteração no que respeita à necessidade de abandonar o seio parental, sendo este encarado como um apoio na criação de condições para o processo de autonomia dos jovens. Por outro lado, embora ainda se verifiquem diferenças de género, existe uma tendência à uniformização entre homens e mulheres, facto que se evidencia no maior investimento na carreira por parte das mulheres, bem como no adiamento da idade para o nascimento do primeiro filho (Ferri \& Smith, 2003). Para Ravn (2005), a adultícia não tem que ser estabelecida pelas responsabilidades de criar família.

Trata-se justamente da permanência em casa dos pais e/ ou da independência financeira proteladas, de acordo com as necessidades económicas e as dificuldades de empregabilidade, que fazem adiar o processo de autonomia dos jovens, tal como o havíamos conhecido até recentemente (Aquilino, 2006). Porém, mediante as inúmeras questões estruturais que parecem fazer diferença no processo de emergência da adultícia, torna-se relevante reflectir se estes factores serão uma justificação suficientemente forte em detrimento dos factores de desenvolvimento que pautam igualmente a vivência dos jovens. Assim, a personalidade, a inteligência e 
especialmente a qualidade das relações estabelecidas com as figuras parentais, os pares e o par romântico são elementos relevantes na mudança da forma como os jovens encaram o futuro.

Nesta medida, sob o ponto de vista da psicologia do desenvolvimento, os jovens são agentes activos no ambiente, não estando absolutamente dependentes do contexto (Arnett, 2006). O autor aponta para estudos (eg., Arnett, 2004) cujas diferenças estruturais não constituem necessariamente um entrave na transição dos jovens, reportando contudo quatro critérios que parecem ser consistentes no processo de transição para a adultícia: (a) aceitação da responsabilidade dos seus actos, (b) tomada de decisões de forma independente, (c) consideração pelos demais, e (d) o tornar-se economicamente independente. Torna-se então pertinente discutir em que medida a relação desenvolvida pelos jovens na família nuclear, em específico com os pais, afecta o processo autonómico, equacionando-se sobretudo se o processo de separação-individuação poderá estar comprometido pelos constrangimentos inerentes a factores estruturais.

Partindo daqui, cabe ressaltar que a individuação constitui um dos processos mais relevantes no desenvolvimento dos jovens, estando desde logo relacionado com a forma como se desenvolve a ligação precoce com os pais. De acordo com Buhl (2008), a ligação afectiva (emotional connectedness) traduz o afecto e a estabilidade na relação, que estão subjacentes ao processo de individuação. A individuação, por seu turno, retrata para os jovens adultos a independência da autoridade parental, transitando de uma autoridade unilateral para uma cooperação e um sistema de mutualidade. Não se trata de uma tarefa de desenvolvimento que se coloca num dado determinado ponto do ciclo vital, mas que se desenrola num contínuo de mudanças sustentadas ao longo das etapas da vida que se vão sucedendo. A este propósito, a proximidade, e especialmente a qualidade afectiva da relação com as figuras parentais, assume o seu papel enquanto moderador da individuação, pelo que maior ligação traduz mais satisfação na relação, mais intimidade e menor índice conflitual.

Os conflitos constituem também matéria na dinâmica relacional e, embora raros os conflitos abertos na idade adulta, existem poucas famílias onde não se registe conflito entre pais e filhos (e.g., Wittmann, Buhl, \& Noack, 2000). Os conflitos não têm que assumir uma significação negativa, pelo que, tal como apontamos anteriormente, a individuação passa pela possibilidade do desacordo e da diferença, recriando uma possibilidade de construção pessoal dos jovens, o que, por outro lado, acentua o desejo de estabelecer níveis mais elevados de individuação (Buhl, 2008). Começa a perceber-se a relação com os pais no início da adultícia numa perspectiva de interdependência, ao invés de independência (e.g., Buhl, 2008; Mattanah, Brand, \& Hancock, 2004). Imamoglu (2003) discute esta questão assumindo que a individuação vs. proximidade/qualidade das relações não são pólos opostos, desempenhando pelo contrário papéis complementares, embora sejam por si só distintos.

Tal como aponta um estudo no contexto da mudança das relações pais-filhos na transição para a adultez, com 257 jovens adultos realizado por Scabini (2000), a qualidade da relação entre pais e filhos implica mudanças da adolescência para a adultícia, envolvendo alterações positivas na proximidade e autonomia dos jovens. Neste sentido, e tentando ir de encontro à questão colocada anteriormente, torna-se evidente que os factores de desenvolvimento são significativos no que concerne aos desafios encarados pelos jovens na transição para a adultícia. No entanto, não são descuradas na "equação" as questões estruturais é pertinente encarar o processo de separação-individuação para além das questões contextuais. $\mathrm{O}$ tema torna-se tão mais relevante quanto mais são investigados e discutidos aspectos relacionados com a dinâmica parental. Assim, hoje em dia é cada vez mais frequente a participação assídua das figuras parentais na vida dos jovens, o que desde logo já havíamos concluído ser um factor facilitador face ao desenvolvimento de níveis de interdependência. Porém, a problemática coloca-se quando existe dificuldade por parte das figuras parentais no que respeita à separação, permitindo a existência de consequências desadaptativas relativas ao processo de separação-individuação. Mayseless e Scharf (2009) sublinham esta posição no seu estudo que pretendeu aceder às dimensões controlo psicológico, individuação e inversão de papéis entre pais e filhas, realizado com 120 jovens entre os 17 e 18 anos, constatando que face à transição do ensino secundário para o serviço militar, ligações desajustadas (pautadas por um elevado controlo, triangulação e desvalorização), prediziam menores níveis de coping e adaptação. Os jovens caracterizados por este tipo de relação com os pais, revelavam ainda maiores níveis de ansiedade de controlo e conflito no processo de independência, traduzidos numa certa imaturidade e em menores índices de independência emocional. Um fenómeno que retrata esta realidade, o estilo parental de envolvimento contínuo e intrusivo, é designado por "pais helicópteros" (helicopter parents, Cline \& Fay, 1990), cuja dinâmica relacional é pautada pela hiperprotecção e o controlo, de tal modo que os pais parecem "pairar" sobre os seus filhos, realizando verdadeiros voos "picados" ao menor sinal do que interpretam como ameaça, não permitindo que os jovens resolvam as suas próprias questões pessoais (Coburn, 2006).

Muitas vezes, estas questões estão relacionadas com o rendimento académico, levando os pais, muitas vezes até sem conhecimento dos seus filhos, a discutirem resultados, notas e desempenhos com docentes, certos que esta atitude é um contínuo dentro das oportunidades de vida que até aí proporcionam aos seus filhos. Além de ser uma postura que encara o ensino do ponto de vista económico, isto é, o pagamento de propinas e o restante elevado investimento necessário à conclusão do primeiro ou do segundo ciclo de estudos superiores, leva muitos pais a defenderem "o seu investimento", pelo que a intromissão no que era tradicionalmente a relação independente e promotora de autonomia aluno-docente, é muitas vezes triangulada pela interferência parental. Ora esta nova realidade constituiu, por si, só um entrave ao processo de separação-individuação, já que não se permite ao jovem adulto defender os seus próprios pontos de vista, lidar com as suas frustrações e reavaliar estratégias de resolução de problemas.

Assim, e numa tentativa de protecção, níveis significativos de ansiedade são transmitidos aos jovens que se encontram menos capazes de lidar com a decepção (Coburn, 2006) e com as realidades de um mercado laboral onde acabarão 
por ser inseridos, caracterizado por momentos de pausa e desemprego, inevitáveis no actual contexto económico. Se quisermos, na tentativa de isolar os filhos de qualquer tipo de dificuldade, salvaguardando a possibilidade do sofrimento, pode estar-se, infelizmente, a aumentar a probabilidade do desenvolvimento desadaptativo. A este propósito, Beyers e Goossens (2004) apresentam um estudo longitudinal, onde se pretendia aceder aos processos de formação da identidade em contextos interpessoais essencialmente com os pais, onde foram avaliados 281 adolescentes entre os 18 e os 24 anos de idade, no qual concluem que o papel parental é dinâmico na medida em que a separação dos jovens pode ser acompanhada pela mudança dos modelos parentais, menos exigentes e controladores, embora capazes de proporcionar apoio, promovendo a autonomia dos jovens na existência de factores de dependência.

Numa revisão da literatura acerca da questão do detachment (Rocha, 2008), verificou-se que na adolescência, embora a construção da identidade e a procura de autonomia sejam processos complementares e reivindiquem um distanciamento relativamente aos pais, parece que concomitantemente não existe um corte emocional na relação entre pais e filhos. Ao invés, o que a literatura parece configurar é que o processo de individuação coexiste com a manutenção da qualidade da relação parental, "parecendo ser este o modo mais adaptativo do sujeito psicológico se constituir enquanto entidade própria, self ou se quisermos, identidade" (Rocha, 2008, p. 61).

\section{Adultos Emergentes - Vocação e trabalho}

Fouad e Bynner (2008) falam do trabalho como um dos contextos fundamentais do desenvolvimento humano. De facto, e desde a infância o trabalho começa a estar presente na vida de cada um de nós. "Do berço ao túmulo" (Bowlby, 1979) é uma frase que facilmente pode ser transposta para a história pessoal relativa ao trabalho. O que queres ser quando fores grande? Já te inscreveste na orientação vocacional para decidires o que queres fazer? Qual é a tua profissão? Enfim, transversalmente o trabalho, a profissão e a carreira estão presentes enquanto definidoras (também) do self. Cada vez mais a carreira é observada enquanto um processo que advém de várias escolhas, escolhas estas que não estão de todo alheias ao contexto pessoal onde o sujeito psicológico se insere. As oportunidades de exploração e apoio são, sem dúvida, um dos factores que mais influenciam o modo de funcionamento pessoal e, em última instância, o modo como construímos a nossa carreira. De acordo com estudos na área do investimento vocacional, sabemos que a qualidade de apego aos pais é um preditor significativo da autoeficácia no processo de decisão vocacional/carreira (Wolfe \& Betz, 2004) e que o apoio parental à autonomia influencia positivamente quer a autoeficácia quer a autonomia no processo de decisão vocacional/carreira. Por fim, que estas últimas dimensões se associam negativamente com a indecisão para a carreira (Guay, Senécal, Gauthier, \& Fernet, 2003).

Com o advento do mercado global a partir dos anos 1970, quer as transições normativas relativas ao trabalho, quer a previsibilidade do caminho das carreiras parecem realida- des longínquas e impossíveis de voltarem a estar presentes na vida da maioria das pessoas. Incerteza, competências, flexibilidade, sociedade de informação, adaptabilidade e exploração são algumas das expressões que entraram em definitivo no léxico de desenvolvimento. O sentido de eficácia e de valência pessoal, importantíssimos no enfrentar destes desafios relativos ao trabalho e à carreira (e.g. Fouad \& Bynner, 2008), advém, segundo o apego (Bowlby, 1988) do modo como vão sendo construídos os modelos de si e dos outros nas relações com os outros significativos, essencialmente na relação com os pais. Nas sociedades ocidentais, os indivíduos não constroem as suas carreiras senão inseridos no seu próprio ecossistema social, o que inclui o contexto histórico, a cultura, a família, os grupos próximos e mais distais, etc. Trata-se daquilo que se denomina de contextualismo de desenvolvimento (Savickas, 2005). A construção de um autoconceito (ou de vários) parte, na infância, da consciência pessoal de que somos diferentes do nosso prestador primário de cuidados. Só na adolescência, com o advento da capacidade reflexiva e de abstracção, existe uma coerência no autoconceito que permite já falar em self. Uma das facetas do self é justamente o autoconceito vocacional.

Os pais são poderosos contribuidores do teor do autoconceito vocacional dos seus filhos; funcionam, de modo vicariante e desde cedo como modelos profissionais. Segundo a teoria da construção da carreira, são cinco os estádios de desenvolvimento na construção da carreira. No primeiro estádio (crescimento) encontramos a tarefa da preocupação com a carreira. Esta está fortemente enraizada na dependência dos pais e aponta claramente para a importância da construção dos modelos internos dinâmicos de si e dos outros, que influenciam o ciclo vital relacional o que inclui, obviamente a esfera do trabalho (vide Blustein, 2008). É o modo preferencial de percepção de si enquanto merecedor de cuidados e carinho e a percepção do outro como disponível e apoiante nos esforços de exploração de si e do mundo, que permitem a adolescentes e adultos explorarem o mundo das profissões e da carreira, certos de que os seus esforços são complementados com uma base segura (Bowlby, 1988; Savickas, 2005).

Porém, o estádio do crescimento, implica também a tarefa do controlo da carreira, isto é, o controlo pessoal que permite que a escolha vocacional seja efectuada pelo próprio sujeito e não deixada ao sabor de um locus de controlo externo que, em última instância, é sinónimo de um jogo de sorte ou azar, ou de uma escolha deixada ao critério de pais ou outros significativos. Trata-se por isso de uma tarefa que implica a independência parental, a autonomia e o investimento pessoais. Embora este estádio de desenvolvimento inclua ainda tarefas adicionais, são a preocupação e o controlo com a carreira as que claramente sugerem o apego e a separação-individuação como sistemas basilares para o desenvolvimento vocacional.

A segunda etapa da construção da carreira foca-se na exploração. É tipicamente um estádio que vai da adolescência à emergência da idade adulta. Em termos gerais trata-se de explorar o self e de o complementar com informação acerca de profissões que possam de algum modo integrar aquilo que se é, com aquilo que se vai ser enquanto profissional. Trata-se ainda de efectuar três tarefas de base, a primeira das 
quais é a da cristalização da preferência vocacional, esta que remete claramente para o sentido da individuação. Explorar-se implica ganhar conhecimento acerca de si mesmo, se diferenciar e, paulatinamente encontrar áreas vocacionais que se integram no autoconceito mais fino.

Nem todas as profissões se adequam ao self, algumas sim, e destas, umas mais que outras. Colocam-se questões acerca da capacidade de colocar em prática as possibilidades em termos de selves profissionais, e vai crescendo a confiança na competência para realizar escolhas. Está na altura de especificar uma escolha, a segunda tarefa de desenvolvimento. Esta particularização permite ainda uma maior diferenciação entre o self e o self dos outros. $\mathrm{O}$ autoconceito vocacional permite que a escolha pessoal por uma mesma profissão torne cada um dos sujeitos num dado grupo diferentes entre si, porque a exploração, as capacidades, os sonhos e a cola entre cada uma destas tarefas não foi a mesma. Finalmente, o sujeito deverá transpor a sua escolha em acções, tornar-se um profissional, actualizar a escolha na transição da escola para o emprego(os).

A influência parental no desenvolvimento pessoal para a carreira dos adolescentes pode ainda (e complementarmente ao posicionamento da teoria da construção da carreira) ser perspectivada do ponto de vista da distinção entre Influências Definidoras e Influências Modeladoras (Middleton \& Laughead, 1993). A primeira respeita essencialmente ao contacto directo, normalmente com os pais, como forma de aquisição de informação acerca das tarefas associadas a diferentes profissões. A segunda respeita a informação obtida por aprendizagem vicariante, onde o jovem, tradicionalmente através de fontes externas à família, observa o desempenho de diferentes profissões, não implicando tal o contacto directo com os actores profissionais.

Deste modo, quer através de um apego seguro, quer através de um processo de separação na manutenção da relação enquanto base segura, os pais continuam presentes na vida dos seus filhos, incluso permitindo a adaptabilidade na construção de sucessivos ciclos de carreira. Isto é, perspectiva-se não só o desenvolvimento de cinco maxiciclos base da construção da carreira ao longo de toda uma vida (crescimento, exploração, estabelecimento, manutenção e desinvestimento), mas também várias etapas de trabalho que impliquem várias vezes este mesmo processo ao longo do ciclo vital. É a partir do apego, do processo subsequente de separação e individuação parental, que o jovem adulto pode encetar uma etapa posterior de maior diferenciação, desta feita no grupo de pares, tendo em conta a esfera do trabalho, da profissão e da carreira.

É ainda através da repetição dos maxiciclos de carreira, tão constantes hoje em dia, que são permitidos aos adultos emergentes percursos de carreira apenas porque suportados nas relações parentais. São estas últimas, as mais adaptativas, aquelas que permitem a exploração de alternativas de carreira, que possibilitam ao sujeito encarar os períodos de não emprego com a manutenção de uma autoestima positiva e, que potenciam a construção de redes sociais (também) de oportunidades de trabalho e de reconhecimento pessoal. Falámos por isso de relações seguras com os pais, onde detachment é sinónimo de manutenção da relação segura e autónoma, que permite a diferenciação do self e a construção de outras relações que, em última instância, repliquem e suportem a adaptabilidade das primeiras.

Assim, embora destacando o papel das figuras parentais ao longo do processo de individuação dos jovens adultos, julgamos pertinente apontar a relevância de outras figuras significativas, tais como os irmãos e os pares, extremamente presentes no processo de crescimento pessoal dos jovens. No ponto que se segue irá ser discutido o papel que os irmãos e os pares (amigos e par romântico) assumem na dinâmica da separação-individuação dos jovens adultos.

\section{Adultos Emergentes - Papel da Fratria e dos Pares}

Tal como temos vindo a apontar, quando abordamos a temática da separação-individuação, torna-se fundamental realizar um enquadramento contextual e relacional em torno das vivências dos jovens. Neste sentido, embora muitas outras questões pudessem ser abordadas, no que concerne às figuras significativas que fazem parte do processo de individuação dos jovens, julgamos pertinente, para além dos pais, dar alguma ênfase ao papel que a fratria e os pares detêm no processo. Cremos serem figuras emocionalmente presentes na vida dos jovens, partilhando vivências com um cariz de complementaridade e similitude que em tudo contribui para o processo de crescimento dos mesmos. Neste sentido, consideramos que a fratria assume um papel fundamental no jogo emocional dos jovens. Desde logo, a fratria constitui o contexto perfeito para o ensaio da vida emocional e relacional futura, pelo que os irmãos exercem uma função constante na aquisição de competências (como a negociação, cooperação e competição), compreensão de pensamentos e sentimentos (que implica a tomada de consciência de uma perspectiva social, da resolução de conflitos e da assunção dos irmãos enquanto portos seguros), o que se torna mais rico quanto mais diversificada for a fratria (Fernandes, 2002).

Este contexto constitui uma fonte privilegiada, onde os jovens aprendem a conviver com os conflitos e afinam a formação da consciência moral e social que vai crescendo e os torna mais maduros e tolerantes à frustração (Gayet, 1993). Desta forma, embora este processo se verifique desde a infância, é na adolescência que a presença da fratria assume contornos mais relevantes no processo de separação-individuação dos jovens. Assim, a ligação com os irmãos beneficia na ponte para a individuação, num jogo de dependência parental e procura de relações no exterior. Para os jovens que entram num processo de autonomia e individuação dos pais, e mesmo estando afectivamente ligados a estes, os irmãos tornam-se frequentemente uma fonte de procura de apoio, no sentido de obter conselhos sobre as dificuldades que vão surgindo ao longo do seu percurso (Seginer, 1998).

Parke et al. (2001) sublinham que os jovens aprendem competências efectivas de resolução de conflitos nas relações de irmãos que mais tarde estendem para a relação com os pares. A este propósito Yeh e Lempers (2004), ao estudarem os potenciais efeitos das relações entre irmãos no desenvolvimento adolescente (entre o início e a adolescência média), observaram em 374 famílias que a qualidade da li- 
gação aos irmãos pode desempenhar um papel relevante no desenvolvimento psicossocial dos jovens. Realizando uma análise longitudinal, em três momentos (com intervalos de um ano), os autores concluíram que jovens que percebiam uma boa relação com os irmãos no momento 1 tendiam a ter uma maior autoestima e um melhor relacionamento com os seus pares no momento 2, o que por seu turno se associava de forma positiva com menos solidão, depressão, menor uso de drogas e menos comportamentos delinquentes no terceiro momento da análise. Os resultados mostraram uma bidireccionalidade entre a qualidade da relação com os irmãos e o estabelecimento de amizades com os pares.

Por conseguinte, embora a relação com os irmãos não detenha o mesmo cariz que a relação com os pais, os irmãos podem muitas vezes ser considerados como figuras de apego, estando presentes ao longo dos desafios que os jovens atravessam (Ryan, 2002). Faz por isso sentido reflectir sobre o seu papel enquanto facilitadores do processo de separação-individuação, num misto de aprendizagem mútua, protecção e valorização pessoal (Bouchey, Shoulberg, Jodl, \& Eccles, 2010). Note-se que jovens adultos com relações afectivas de qualidade com os irmãos assumem maior segurança na relação com o exterior, estando ao mesmo tempo mais disponíveis e tolerantes para solicitar ajuda perante as suas dificuldades (Fernandes, 2002). Os pares por sua vez constituem figuras igualmente significativas para os jovens, muitas vezes com uma proximidade ao papel dos irmãos, especialmente quando falamos de filhos únicos ou quando os irmãos têm muita diferença de idade. Desta feita, tal como acontece com os irmãos, os jovens investem em relações igualmente privilegiadas com os pares, começando um ensaio de um novo papel, onde há uma reciprocidade ou simetria entre a prestação e a recepção de cuidados, o que os descentra da complementaridade vivida nas ligações da infância (Matos, 2003; Rocha, 2008). Desta forma, ao contrário do que sucedia na infância, a transição para a fase adulta é pautada por um maior investimento nos pares. Partindo sempre da noção de base segura, os jovens adultos encontram-se mais disponíveis para explorar a possibilidade de estabelecer novas relações (Nickerson \& Nagle, 2005), recriando um intermédio entre a aprendizagem do "tornar-se uma figura de vinculação" e a necessidade de "ser uma figura vinculada" (Soares, 2004). Meeus, Iedema, Maassen e Engels (2005) sugerem o contexto de pares relevante enquanto ensaio de formas de ser, estar e pensar mais diferenciados, que recriam e validam o sentimento de identidade pessoal. Assim, a aquisição de uma progressiva maturidade emocional faz com que o jovem procure novas experiências sempre com o intuito de aquisição de maior autonomia e confiança em si mesmo. A literatura assume que este processo crescente de procura de autonomia e interacção com o exterior se faz acompanhar pelo desenvolvimento dos laços e relações afectivas (Guedeney \& Guedeney, 2004).

Sob a égide da procura crescente dos pares como fonte de apoio, e seguindo uma lógica da "aprendizagem" e de funcionamento em termos de relações emocionais pautadas pela reciprocidade, uma nova relação de intimidade aparece dentro da ordem geral das relações de pares: a relação amorosa. Sneed et al. (2006) forneceram dados indiciadores de que o contacto com a família tende a diminuir ao mesmo tempo que a instrumentalidade na autonomia (o grau no qual um sujeito toma responsabilidade pelas suas acções, ou, por outras palavras, é independente) quer financeira quer romântica, tendem a aumentar na transição para a jovem adultícia. Esta diminuição do recurso parental parece aliar-se ao género, com os rapazes a apresentarem um padrão de maior decréscimo que as raparigas. Em última instância, este movimento de desenvolvimento promove o bem-estar pessoal e a adaptabilidade em ambos os domínios, sendo aquele que aqui interessa é sobretudo o contexto romântico.

Ao longo da adolescência, a literatura refere um segundo processo de separação-individuação (Blos, 1979) que permite aos jovens um paulatino envolvimento com os pares (Overbeek, Vollebergh, Engels, \& Meeus, 2003) e, em última instância, com o par amoroso (Rocha, 2008). A partir da plena adolescência, as relações românticas passam a destacar-se na vida da maioria dos jovens, chegando a constituir-se, pelo menos algumas, aquelas onde existe continuidade íntima, em relações de apego (Hazan \& Zeifman, 1999; Rocha 2008). A continuidade dessas relações, ou a procura de proximidade continuada na relação amorosa pode, então, em alguns casos permitir a existência em conjunto das componentes de porto e base seguros e protesto de separação que se apresenta na literatura como vinculações totais (Hazan \& Zeifman, 1999). Foi com Hazan e Shaver (1994) que se começa a explorar a possibilidade de que algumas relações românticas se pudessem constituir em relações de apego (hoje já uma certeza). É neste contexto que surge o modelo da transferência das componentes de apego dos pais aos pares (Fraley \& Davis, 1997, Hazan \& Zeifman, 1999; Mikulincer, Gillath, \& Shaver, 2002; Trinke \& Bartholomew, 1997). O modelo supõe que a importância dos pais na hierarquia relacional dos filhos decresce à medida que o ciclo vital vai decorrendo, porém, os pais jamais deixam de pertencer a esta hierarquia de apego como figuras significativas. Este pressuposto levanta, então, a questão da autonomia afectiva relativamente aos pais e por isso mesmo do processo de separação-individuação, como condição sine-qua-non para o estabelecimento das relações amorosas seguras.

Com o estudo de Friedelmeier e Granqvist (2006), no qual se pretendeu analisar prospectivamente, em adolescentes, o modo como eram transpostas as componentes de apego dos pais aos pares, mas também no de Markiewitcz, Lawford, Doyle e Haggart (2006) que estudou a procura das componentes de apego de procura de proximidade, porto e base seguros em adolescentes relativamente a pais e pares, percebe-se que a existência do par amoroso na equação relacional é uma condição importantíssima quer para a extensão da transferência das componentes, quer para a rapidez em que o processo ocorre. São ainda Trinke e Bartholomew (1997) a referirem estas mesmas conclusões, embora acrescentando novo contributo teórico, ao encontrarem evidência de que a segurança de apego aos pais influencia positivamente o recurso ao par amoroso. O recurso ao par amoroso enquanto figura de apego parece de facto sustentar-se na premissa da segurança aos pais. Ao contrário, o estudo de Rocha (2008) não encontrou evidência de que assim seja, conquanto a amostra estudada fosse essencialmente adolescente e não jovem adulta, o que pode de algum modo explicar estes resultados. Na adolescência, mais que a escolha do par 
amoroso depender dos factores aliados aos modelos internos dinâmicos, trata-se de uma questão mais contextual, isto é, o par amoroso é apenas um par entre o grupo alargado de pares, pelo menos inicialmente (Rocha, 2008).

Assim, as relações seguras na teoria do apego (Ainsworth, Blehar, Waters, \& Wall, 1978, Bowlby, 1988) apresentam-se como aquelas relações em que fruto da procura de proximidade relacional continuada a figura significativa é procurada como fonte de apoio e cuidados, e é consistentemente responsiva e disponível. Porém, permite paralelamente a exploração pessoal daquele que está "vinculado com", na certeza de que este último pode voltar à relação e contar com ela mesmo em situação de desacordo. Por seu turno, a presença destas três componentes permite ainda a expressão do protesto de separação, que na adultícia se expressa na maioria das vezes pela expressão emocional da saudade.

\section{Considerações Finais}

A importância da qualidade das relações primárias no futuro relacional de cada ser humano constitui um dos pressupostos teóricos da teoria do apego (Ainsworth, 1969; Bowlby, 1979). Porém, existe um olhar complementar na mesma teoria do apego que encara o erguer do edifício pessoal em termos de construções sucessivas e reorganizações pessoais que, inevitavelmente ajudam cada um de nós a poder observar-se diferencialmente ao longo do ciclo vital. Esta perspectiva tem em conta não só a integração das experiências pessoais, à medida que ocorrem com diferentes personagens que vão sendo acrescentadas ao elenco de vida, mas também a forma como o desenvolvimento cognitivo, a estrutura mental, é capaz de lidar e absorver essas experiências. Assim, até determinado limiar de desenvolvimento, o final da infância, não é possível prescindir dos prestadores de cuidados iniciais, mas a partir daí, a estruturação quer social quer mental, começa a permitir o enquadramento de actores necessariamente mais parecidos em estatuto com cada um de nós, os pares (Rocha, 2008).

Estes não são de imediato tão importantes quanto os pais, e muitos não o serão nunca, porém são essenciais ao processo de nos tornarmos diferentes. No entanto ser diferente de uns implica ser igual a outros e, neste processo sequencial alguns pares são especiais e permitem uma nova revolução pessoal: ser diferente de todos e igual a si mesmo. Neste processo passam anos e, nestes anos, revisita-se a vivência pessoal sempre de modo, mesmo que ligeiro, diverso (vide Kegan, 1982). Pese embora se mantenha uma constância pessoal conserva-se também a capacidade de mudar. As regularidades do desenvolvimento, cada idade ou grupo de idades que se agrupam em infância, adolescência, adultícia e maturidade apresentam também regularidades e consequentes mudanças às quais a teoria do apego não é indiferente.

$\mathrm{O}$ apego, tem, pois o processo complementar da exploração, sem o qual não seria possível que a primeira tivesse uma qualidade adaptativa e, mantendo presente a sua qualidade de sistema sobrevivência, permite também que, após o desaparecimento dos pais, se possa recorrer ao par romântico na busca da base segura sem a qual não é possível sequer (sobre)viver. A exploração faz parte do processo de construção da identidade (Erikson, 1950; Marcia, 1966).
Assim, o apoio parental diminui com a idade, aumentando o compromisso identitário relacional com outros além dos pais e com a sociedade no geral (Meeus et al., 2005). É de facto no contexto de relações seguras com os pais, que permitem a separação e o pronuncio da individuação, que se criam as condições para o advento de relações românticas ajustadas na jovem adultícia.

Em suma, a noção de "adultos emergentes" parece ir de encontro à vivência de uma separação-individuação capaz de manter ligações de qualidade com as figuras significativas de afecto. A entrada na adultícia sugere estar agora pautada por aspectos distintos de outrora, facto que se prende a aspectos estruturais e de desenvolvimento de cada indivíduo. Todavia, torna-se claro que o jogo relacional com as figuras parentais é um contínuo e assume relevância nas decisões dos jovens, contrariando a ideia de que os factores estruturais podem ser determinantes por si só. Esta perspectiva sublinha a ideia de que o desapego é ilusório na adolescência, assim como, no desenrolar da adultícia, a diferença evidencia-se antes pela alteração dos comportamentos de apego (Fleming, 2005). Fala-se de um complemento de proximidade emocional que está naturalmente implícito, mas, ao mesmo tempo, permite ao jovem a experienciação da distância, questão que é fundamental para o processo de autonomia. Finalmente, paralelamente às figuras parentais, outras figuras significativas, tais como os irmãos e os pares, assumem um papel complementar nesta dinâmica de crescimento pessoal. Neste contexto, o processo relacional é percebido pelos irmãos e pares de forma horizontal, muitas vezes mais próximos da realidade vivencial dos jovens, pelo que o cariz de partilha, compreensão e ajuda activa merecem atenção quando se aborda a dinâmica implícita na transição para a adultícia.

\section{Referências}

Ainsworth, M. D. S. (1969). Maternal sensitivity scales. Baltimore. MD: John Hopkins University Press.

Ainsworth, M. D. S., Blehar, M. C., Waters, E., \& Wall, S. (1978). Patterns of attachment: A psychological study of the strange situation. Hillsdale, NJ: Erlbaum.

Aquilino, W. S. (2006). Family relationships and support systems in emerging adulthood. In J. J. Arnett \& J. Tanner (Eds.), Coming of age in the $21^{\text {st }}$ century: The lives and contexts of emerging adults (pp.193-218). Washington DC: American Psychological Association.

Arnett, J. J. (2004). Emerging adulthood: The winding road from the late teens through the twenties. New York: Oxford University Press.

Arnett, J. J. (2006). Emerging adulthood in Europe: A response to Bynner. Journal of Youth Studies, 9, 111-123.

Beyers, W., \& Goossens, L. (2004). Contributions of parenting to the separation-individuation process in late adolescence: A threewave longitudinal study. Symposium conducted at the 10th biennial meeting of the Society for Research on Adolescence (SRA), Baltimore, USA.

Blos, P. (1979). The adolescent passage. New York: International Universities Press. 
Blustein, D. L. (2008). The role of work in psychological health and well-being: A conceptual, historical, and public policy perspective. American Psychologist, 63, 228-240

Bowlby, J. (1979). The making and breaking of affectional bonds. London: Routledge.

Bowlby, J. (1988). A secure base: Parent-child attachment and healthy human development. London: Basic Books.

Bouchey, H. A., Shoulberg, E. K., Jodl, K. M., \& Eccles, J. S. (2010). Longitudinal links between older sibling features and younger sibling's academic adjustment during early adolescence. Journal of Educational Psychology, 102(1), 197-211.

Bretherton, I. (1992). The origins of attachment theory: John Bowlby and Mary Ainsworth. Developmental Psychology, 28, 759-775.

Bronfenbrenner, U. (1996). A ecologia do desenvolvimento humano: Experimentos naturais e planejados. Porto Alegre: Artes Médicas.

Buhl, H. M. (2008). Significance of individuation in adult childparent relationships. Journal of Family Issues, 29, 262-281.

Bynner, J. (2005). Rethinking the youth phase of the life-course: The case for emerging adulthood? Journal of Youth Studies, $8,367-384$

Claussen, A. H., \& Crittenden, P. M. (2000). Maternal sensitivity. In P. M. Crittenden, \& A. H. Claussen (Eds.), The organization of attachment relationships. Maturation, culture and context (pp. 115-124). New York: Cambridge University Press.

Cline, F. W., \& Fay, J. (1990). Parenting with love and logic: Teaching children responsibility. Colorado Springs: Pinon Press.

Coburn, K. L. (2006). Organizing a ground crew for today's helicopter parents. About Campus, 11, 9-16.

Collins, W. A., \& Sroufe, L. A. (1999). Capacity for intimate relationships: A developmental construction. In W. Furman, B. B. Brown \& C. Feiring (Eds.), The development of romantic relationships in adolescence (pp. 125-147). NY: Cambridge University Press.

Eccles, J., Templeton, J., Barber, B., \& Stone, M. (2003). Adolescence and emerging adulthood: the critical passage ways to adulthood. In M. H. Bornstein, L. Davidson, C. L. M. Keyes \& K. A. Moore (Eds.), Well-beings: Positive development across the life course (pp. 383-406). Mahwah, NJ: Lawrence Erlbaum Associates.

Erikson, E. (1950). Childhood and society. New York: Norton

Fernandes, O. M. (2002). Semelhanças e diferenças entre irmãos. Lisboa: Climepsi Editores.

Ferri, E., \& Smith, K. (2003). Partnerships and parenthood. In E. Ferri, J. Bynner \& M. E. (Eds.), Wadsworth, changing Britain, changing lives: Three generations at the turn of the century (pp. 105-132). London: Institute of Education.

Fleming, M. (2003). O risco de não correr risco nenhum: Impasses do desenvolvimento psicológico adolescente. Revista Portuguesa de Psicanálise, 24, 97-105.

Fleming, M. (2005). Entre o medo e o desejo de crescer: Psicologia da adolescência. Porto: Edições Afrontamento.

Fouad, N. A., \& Bynner, J. (2008). Work transitions. American Psychologist, 63, 241-251.

Fraley, R. C., \& Davis, K. (1997). Attachment formation and transfer in young adults' close relationships and romantic relationships. Personal Relationships, 4, 131-144.
Friedlmeier, W., \& Granqvist, P. (2006). Attachment transfer among Swedish and German adolescents: A prospective longitudinal study. Personal Relationships, 13, 261-279.

Gayet, D. (1993). Les relations fraternelles: Approches psychologiques et anthropologiques des fratries. Paris: Delachaux et Niestlé.

Grossmann, K. E., \& Grossmann, K. (2004). Universality of human social attachment as an adaptive process. In C. S. Carter, L. Ahnert, K. E. Grossmann, S. B. Hardy, M. E. Lamb, S. W. Porges, \& N. Sachser (Eds.), Attachment and bonding: A new synthesis (pp.199-229). Cambridge; MA: The MIT Press.

Guay, F., Senecal, C., Gauthier, L., \& Fernet, C. (2003). Predicting career indecision: A self-determination theory perspective. Journal of Counseling Psychology, 50, 165-177.

Guedeney, N., \& Guedeney, A. (2004). Vinculação: conceitos e aplicações. Lisboa: Climepsi Editores.

Hazan, C., \& Shaver, P. R. (1994). Attachment as an organizational framework for research on close relationships. Psychological Inquiry, 5, 1-22.

Hazan, C., \& Zeifman, D. (1999). Pair bonds as attachments: Evaluating the evidence. In Jude Cassidy \& Phillip R. Shaver (Eds.), Handbook of attachment: Theory, research, and clinical applications (pp. 336-354). New York: The Guilford Press.

Hendry, L. B., \& Kloep, M. (2002). Lifespan development: Resources, challenges and risks. London: Thomson Learning.

Imamoglu, E. O. (2003). Individuation and relatedness: Not opposing but distinct and complementary. Genetic, Social and General Psychology Monographs, 129, 367-402.

Kegan, R. (1982). The evolving self: Problem and process in human development. Cambridge, MA: Harvard University Press.

Luthar S. S., \& Goldstein A. (2004). Children's exposure to community violence: Implications for understanding risk and resilience. Journal of Clinical Child and Adolescent Psychology, 33, 499-505.

Nickerson, A. B., \& Nagle, R. J. (2005). Parent and peer attachment in late childhood and early adolescence. Journal of Early Adolescence, 25, 223-249.

Marcia, J. E. (1966). Development and validation of ego identity status. Journal of Personality and Social Psychology, 3, 551-558.

Markiewicz, D., Lawford, H., Doyle, A. B., \& Haggart, N. (2006). Developmental differences in adolescents' and young adults' use of mothers, fathers, best friends, and romantic partners to fulfil attachment needs. Journal of Youth and Adolescence, $35,127-140$.

Matos, P.M. (2003). O conflito à luz da teoria da vinculação. In M. E. Costa (Ed.), Gestão de conflitos na escola (pp.144-191). Lisboa: Universidade Aberta.

Mattanah, J. F., Brand, B. L., \& Hancok, G. R. (2004). Parental attachment, separation-individuation, and college student adjustment: A structural equation analysis of meditational effects. Journal of Counseling Psychology, 51, 213-225.

Mayseless, O., \& Scharf, M. (2009). Too close for comfort: Inadequate boundaries with parents and individuation in late adolescent girls. American Journal of Orthopsychiatry, 79, 191-202. 
Meeus, W., Iedema, J., Maassen, G., \& Engels, R. (2005). Separation-individuation revisited: On the interplay of parentadolescent relations, identity and emotional adjustment in adolescence. Journal of Adolescence, 28, 89-106.

Middleton, E., \& Loughead, T. A. (1993). Parental influence on career development: An integrative framework for adolescent career counseling. Journal of Career Development, 3, 161173.

Mikulincer, M., Gillath, O., \& Shaver, P. R. (2002). Activation of the attachment system in adulthood: Threat-related primes increase the accessibility of mental representations of attachment figures. Journal of Personality and Social Psychology, 83, 881-895.

Nickerson, A. B., \& Nagle, R. J. (2005). Parent and peer attachment in late childhood and early adolescence. Journal of Early Adolescence, 25, 223-249.

Overbeek, G., Vollebergh, W., Engels, R. C. M. E., \& Meeus, W. (2003). Parental attachment and romantic relationships: Associations with emotional disturbance during late adolescence. Journal of Counselling Psychology, 50, 28-39.

Parke, R. D., Kim, M., Flyr, M., McDowell, D. J., Simpkins, S. D., Killian, C. M., \& Wile, M. (2001). Managing marital conflict: Links with children's peer relationships. In J. H. Grych \& F. D. Fincham (Eds.), Interparental conflict and child development: Theory, research, and applications (pp. 291-314). Cambridge: Cambridge University Press.

Ravn, M. N. (2005). A matter of free choice? Some structural and cultural influences on the decision to have or not to have children in Norway. In C. B. Douglass (Ed.), Barren States. The population implosion in Europe (pp. 29-47). Oxford: Berg Publishers.

Rocha, M. (2008). O desenvolvimento das relações de vinculação na adolescência: Associações entre contextos relacionais com pais, pares e par amoroso. Tese de Doutorado, Universidade do Porto, Porto, Portugal.

Rocha, M., Mota, C. P., \& Matos, P. M. (2011). Vinculação à mãe e ligação aos pares na adolescência: O papel mediador da autoestima. Análise Psicológica, 2, 185-200.

Ryan, E. (2002). Assessing sibling attachment in the face of placement issues. Clinical Social Work Journal, 30, 77-93.
Savickas, M. L. (2005). The theory and practice of career construction. In S. D. Brown \& R. W. Lent (Eds.), Career development and counseling: Putting theory and research to work (pp. 42-70). Hoboken, NJ: Wiley.

Scabini, E. (2000). Parent-child relationships in Italian families: Connectedness and autonomy in the transition to adulthood. Psicologia: Teoria e Pesquisa, 16, 23-30.

Seginer, R. (1998). Adolescents' perceptions of relationships with older sibling in the context of other close relationships. Journal of Research on Adolescence, 8, 287-308.

Sneed, J. R., Johnson, J. G., Coehen, P., Gillian, C., Chen, H., Crawford, T., \& Kasen, S. (2006). Gender differences in the age-changing relationships between instrumentally and family contact in emerging adulthood. Developmental Psychology, 42, 787-797.

Soares, I. (2004, Dezembro). Vinculação e adolescência patológica. Trabalho apresentado no congresso de Adolescência: Identidade e Modernidade, Lisboa, Portugal.

Trinke, S. J., \& Bartholomew, K. (1997). Hierarchies of attachment relationships in young adulthood. Journal of Social and Personal Relationships, 14, 603-625.

Wittmann, S., Buhl, H. M., \& Noack, P. (2000). Arbeitsbericht aus dem Forschungsprojekt "Erwachsene und ihre Elten," 1999 bis 2000 [Research report from the research project "Adults and their parents", 1999-2000]. Jena, Germany: FriedrichSchiller-University Jena.

Wolfe, J. B., \& Betz, N. E. (2004). The relationship of attachment variables to career decision-making self-efficacy and fear of commitment. Career Development Quarterly, 52, 363-369.

Yeh, H. C., \& Lempers, J. D. (2004). Perceived sibling relationships and adolescent development. Journal of Youth and Adolescence, 33, 133-147. 